\title{
Raised plasma homocysteine as a risk factor for retinal vascular occlusive disease
}

Mark Cahill, Maria Karabatzaki, Ray Meleady, Helga Refsum, Per Ueland, Denis Shields, David Mooney, Ian Graham

The Research

Foundation, The Royal Victoria Eye and Ear

Hospital, Adelaide

Road, Dublin 2,

Ireland

M Cahill

M Karabatzaki

D Mooney

Department of Cardiology, The Adelaide-Meath Hospital, incorporating The National Children's Hospital, Tallaght, Dublin 24, Ireland R Meleady

I Graham

Department of Pharmacology, University of Bergen, Armauer Hansens Hus, 5021 Bergen,

Norway

H Refsum

P Ueland

Department of Clinical Pharmacology, The Royal College of Surgeons in Ireland, St. Stephen's Green, Dublin 2, Ireland D Shields

Correspondence to: Mr Mark Cahill, Department of Ophthalmology, Mater Misericordiae Hospital, Eccles Street, Dublin 7, Ireland

Accepted for publication 15 September 1999

\begin{abstract}
Backgroundlaims-A moderately elevated plasma concentration of the sulphur amino acid homocysteine is an independent risk factor for atherosclerotic vascular disease. Many of the risk factors associated with coronary, cerebral, and peripheral atherosclerotic vascular disease are common to retinal vascular occlusive disease but it is unclear whether elevated plasma concentrations of homocysteine are also associated with such disease. This study assessed the relation between retinal vascular occlusive disease and elevated levels of plasma total homocysteine (tHcy).
\end{abstract}

Methods-A retrospective case-control study involving hospital based controls and cases with retinal artery, central retinal vein (including hemiretinal vein), and branch retinal vein occlusions was performed. The relation between elevated tHcy, defined as a level greater than or equal to $12 \mu \mathrm{mol} / 1$ and risk of retinal vascular occlusive disease was examined. Results -87 cases of retinal vascular occlusive disease including 26 cases of retinal artery occlusion, 40 cases with central retinal vein occlusion, and 21 cases of branch retinal vein occlusion were compared with 87 age matched controls. Mean tHcy levels were higher in all disease groups and this difference was significant in patients with retinal artery occlusions $(p=0.032)$ and patients with central retinal vein occlusion $(p=0.0001)$. When adjusted for known cardiovascular risk factors, tHcy was an independent risk factor for retinal vascular occlusive disease (OR 2.85 (95\% CI 1.43-5.68)).

Conclusions-Elevated tHcy is an independent risk factor for retinal vascular occlusive disease. Assessment of tHcy may be important in the investigation and management of patients with retinal vascular occlusive disease.

(Br F Ophthalmol 2000;84:154-157)

The rare syndrome of homocystinuria was first described in 1962 among subjects with mental retardation, ocular and skeletal abnormalities, and a high risk of thromboembolism. ${ }^{1}$ In such individuals whose plasma total homocysteine (tHcy) concentrations are greatly elevated (often in excess of $100 \mu \mathrm{mol} / \mathrm{l}$ ), the underlying defect is usually one of inherited dysfunction of the enzyme cystathionine B-synthase (CBS). ${ }^{2}$ The observation of marked atherosclerotic-like lesions in two neonates with homocystinuria, one with CBS deficiency and one with a rare defect in cobalamin metabolism, led McCully to propose the hypothesis that homocysteine is a causative factor for atherosclerotic vascular disease. ${ }^{3}$ This hypothesis has been supported by evidence from many further studies demonstrating a significant relation between elevated tHcy concentrations and risk of venous thrombosis, coronary, cerebral, and peripheral vascular disease. ${ }^{4-8}$

Recently, it has become clear that apart from rare genetic defects which are associated with greatly elevated tHcy levels, certain nutritional deficiencies are important and common determinants of elevated tHcy concentration. ${ }^{9}$ In particular, plasma concentrations and dietary intake of folate, vitamin $\mathrm{B} 6$, and $\mathrm{B} 12$ relate inversely to the tHcy level. ${ }^{9}$ Supplementation with such vitamins lowers tHcy levels and may reduce vascular disease risk. ${ }^{810}$

While retinal vascular occlusive disease and coronary, cerebral, and peripheral vascular disease have a number of risk factors in common including systemic hypertension and smoking, the classic cardiovascular risk factors do not fully explain these relations. ${ }^{11-16}$ To date, little information exists about the possibility that elevated tHcy might increase the risk of retinal vascular disease. ${ }^{17-19}$ The present study was undertaken to assess the relation between retinal vascular occlusive disease and moderately elevated fasting levels of tHcy.

\section{Subjects and methods}

CASES

Using the records of the photographic department of the Royal Victoria Eye and Ear Hospital to identify patients with retinal vascular occlusive disease, a retrospective case-control study was performed. Eighty seven cases with clinical and objective investigational evidence of retinal vascular occlusive disease were studied including 40 cases of central and hemiretinal vein occlusion (which were considered together), 21 cases of branch retinal vein occlusion, and 26 cases of retinal artery occlusion (central and branch were included together). To minimise the influence of the vascular event on plasma tHcy concentrations and to reduce bias caused by risk factor treatment only cases diagnosed between 3 and 12 months before the study were included. Exclusion criteria were recent major systemic illness (including myocardial infarction), evidence of vasculitis, renal, hepatic, or thyroid disease, cardiomyopathy, pregnancy, psychiatric illness, chronic alcohol abuse, anticonvul- 
Table 1 Raised $t H c y$ as a risk factor for retinal vascular occlusive disease. Age, sex, and blood levels of tHcy, total cholesterol, and creatinine in controls and cases

\begin{tabular}{|c|c|c|c|c|c|c|}
\hline & \multirow[b]{2}{*}{ Controls } & \multicolumn{5}{|l|}{ Cases } \\
\hline & & All & Arterial & All vein & Central vein & Branch vein \\
\hline No of subjects & 87 & 87 & 26 & 61 & 40 & 21 \\
\hline Mean age (years) & 70.2 & 68.5 & 66.8 & 69.2 & 70.2 & 67.2 \\
\hline Sex, $\%$ male & 41.2 & 55.2 & 73.0 & 47.5 & 50.0 & 42.8 \\
\hline $\mathrm{p}$ Value & & 0.095 & 0.009 & 0.565 & 0.473 & 0.901 \\
\hline GM fasting tHcy $(\mu \mathrm{mol} / \mathrm{l})$ & 10.7 & 12.9 & 12.9 & 13.0 & 13.7 & 11.7 \\
\hline p Value & & $<0.0001$ & 0.032 & $<0.0001$ & 0.0001 & 0.097 \\
\hline GM serum creatinine $(\mu \mathrm{mol} / \mathrm{l})$ & 92 & 95 & 99 & 93 & 96 & 87 \\
\hline p Value & & 0.723 & 0.405 & 0.989 & 0.640 & 0.466 \\
\hline GM fasting total cholesterol & & & & & & \\
\hline$(\mu \mathrm{mol} / \mathrm{l})$ & 5.8 & 5.6 & 5.7 & 5.6 & 5.5 & 5.8 \\
\hline p Value & & 0.783 & 0.453 & 0.431 & 0.284 & 0.957 \\
\hline
\end{tabular}

sant therapy, and recent (within 3 months) exposure to nitrous oxide.

\section{CONTROLS}

Eighty seven hospital based controls were age matched and had no history or clinical evidence of retinal vascular disease. The majority of controls were patients attending for routine cataract extraction $(n=59)$ while other controls had a range of surgical procedures including retinal detachment repair $(n=8)$, trabeculectomy $(n=7)$, ptosis repair $(n=2)$, squint repair $(n=1)$, secondary hydroxyapatite implant $(n=1)$, and excision of pterygium $(n=1)$. A smaller number of controls were hospital staff members $(n=8)$. Exclusion criteria were as in the case group.

\section{VARIABLES EXAMINED}

Demographic, cardiovascular risk factors, and diagnostic data were recorded for each subject based on a standardised format. Diagnostic data consisted of biochemical, haematological, and endocrine variables that are known to alter tHcy levels. All blood samples were taken fasting (samples were taken preoperatively in controls requiring surgical treatment) and analysed using standard automated laboratory techniques. Blood samples for tHcy were immediately placed on ice, centrifuged at $4^{\circ} \mathrm{C}$ and $3500 \mathrm{rpm}$ for 6 minutes within 1 hour and the resultant plasma supernatant was aspirated, frozen, and stored at $-70^{\circ} \mathrm{C}$. tHcy was determined by high performance liquid chromatography and fluorescence detection. ${ }^{20}$

\section{STATISTICAL ANALYSIS}

All of the controls were compared with cases in each of four categories including all cases of retinal artery occlusions, all cases of retinal vein occlusions, cases of central retinal vein occlusions (including hemiretinal vein occlusions), and cases of branch retinal vein occlusions. An elevated tHcy level was defined as greater than or equal to $12 \mu \mathrm{mol} / 1$. Logarithmic transformations and geometric means were used for variables showing a marked positive skew. Univariate analysis was carried out initially to determine the significance of associations between the controls and each of the four groups of patients with regard to the previously outlined variables using the Student's $t$ test for normally distributed continuous variables, the MannWhitney $U$ test for continuous variables with a skewed distribution, and the $\chi^{2}$ test for categorical variables. Single logistic regression models were used to examine the relation between elevated tHcy and known risk factors including hypertension and glaucoma in venous occlusive disease and hypertension and previous carotid surgery in arterial occlusive disease.

Table 2 Raised $t H c y$ as a risk factor for retinal vascular occlusive disease. Distribution of risk factors for cardiovascular and retinal vascular occlusive disease

\begin{tabular}{|c|c|c|c|c|c|c|}
\hline & \multirow[b]{2}{*}{ Controls } & \multicolumn{5}{|l|}{ Cases } \\
\hline & & All & Arterial & All vein & Central vein & Branch vein \\
\hline No of subjects & 87 & 87 & 26 & 61 & 40 & 21 \\
\hline \multirow{2}{*}{$\begin{array}{l}\text { Lipid lowering therapy (\%) } \\
\text { p Value }\end{array}$} & 4.6 & 6.9 & 1.5 & 4.9 & 7.5 & 0.0 \\
\hline & & 0.744 & 0.197 & 1.00 & 0.677 & 1.00 \\
\hline \multicolumn{7}{|l|}{ Treatment for hypertension } \\
\hline$(\%)$ & 36.8 & 58.6 & 69.2 & 54.1 & 52.5 & 57.1 \\
\hline p Value & & 0.006 & 0.007 & 0.037 & 0.140 & 0.145 \\
\hline \multirow{2}{*}{$\begin{array}{l}\text { Current smokers (\%) } \\
\text { p Value }\end{array}$} & 32.2 & 17.2 & 19.2 & 16.4 & 15.0 & 19.0 \\
\hline & & 0.035 & 0.303 & 0.048 & 0.069 & 0.359 \\
\hline \multirow{2}{*}{$\begin{array}{l}\text { Diabetes mellitus (\%) } \\
\text { p Value }\end{array}$} & 8.0 & 11.5 & 15.4 & 9.8 & 5.0 & 19.0 \\
\hline & & 0.669 & 0.273 & 0.933 & 0.718 & 0.218 \\
\hline \multirow{2}{*}{$\begin{array}{l}\text { Ischaemic heart disease (\%) } \\
\text { p Value }\end{array}$} & 16.1 & 23.0 & 27.0 & 21.3 & 27.5 & 9.5 \\
\hline & & 0.339 & 0.252 & 0.553 & 0.207 & 0.732 \\
\hline \multirow{2}{*}{$\begin{array}{l}\text { Previous carotid } \\
\text { endarterectomy (\%) } \\
\text { p Value }\end{array}$} & 0.0 & 6.9 & 19.2 & 1.6 & 0.0 & 4.7 \\
\hline & & 0.028 & 0.0004 & 0.416 & 1.00 & 0.201 \\
\hline \multirow{2}{*}{$\begin{array}{l}\text { Previous TIA/CVA (\%) } \\
\text { p Value }\end{array}$} & 4.6 & 12.6 & 15.4 & 11.5 & 12.5 & 9.5 \\
\hline & & 0.105 & 0.080 & 0.201 & 0.138 & 0.330 \\
\hline \multirow{2}{*}{$\begin{array}{l}\text { Treatment for glaucoma (\%) } \\
\text { p Value }\end{array}$} & 10.0 & 17.0 & 4.0 & 23.0 & 22.5 & 19.0 \\
\hline & & 0.11 & 0.411 & 0.020 & 0.046 & 0.13 \\
\hline
\end{tabular}


Table 3 Raised $t$ Hcy as a risk factor for retinal vascular occlusive disease. Odds ratios for retinal vascular occlusive disease conferred by elevated tHcy in different case groupings

\begin{tabular}{|c|c|c|c|c|}
\hline \multirow[b]{2}{*}{ Versus 87 controls } & \multicolumn{2}{|l|}{ Univariate } & \multicolumn{2}{|c|}{ Multivariate adjusted } \\
\hline & Odds ratio & $95 \% C I$ & Odds ratio & $95 \% C I$ \\
\hline All cases $(n=87)$ & 2.89 & $1.52-5.50$ & $2.85^{\star}$ & $1.43-5.68$ \\
\hline Arterial $(n=26)$ & 2.53 & $1.02-6.29$ & $2.02 \dagger$ & $0.76-5.33$ \\
\hline All vein $(n=61)$ & 3.05 & $1.52-6.13$ & $3.33^{\star}$ & $1.56-7.14$ \\
\hline Central vein $(n=40)$ & 4.00 & $1.81-8.82$ & $4.01^{\star}$ & $1.70-9.48$ \\
\hline Branch vein $(n=21)$ & 1.82 & $0.66-4.97$ & $1.87^{\star}$ & $0.64-5.42$ \\
\hline
\end{tabular}

^Terms were included in the model for cholesterol, glaucoma, hypertension, diabetes mellitus, and smoking.

†Terms included were as listed above $\left({ }^{\star}\right)$, but excluding glaucoma.

\section{Results}

AGE, SEX, AND RETINAL VASCULAR OCCLUSIVE DISEASE

Twenty six cases of retinal artery occlusion (mean age 66.8 years) and 61 cases of retinal vein occlusion (mean age 69.2 years) were compared with 87 controls (mean age 70.2 years). Forty eight per cent of the study participants were male $(n=84)$ and while there were similar proportions of males to females in the control and venous occlusion groups there was a significantly higher proportion of males with retinal artery occlusions $(p=0.009)$ (Table 1).

TRADITIONAL RISK FACTORS FOR CARDIOVASCULAR AND RETINAL VASCULAR OCCLUSIVE DISEASE

No significant differences were noted between cases and controls in the mean serum total cholesterol levels, use of lipid lowering agents, prevalence of diabetes, ischaemic heart disease, previous transient ischaemic attack, or stroke (Table 2). A significantly higher proportion of cases of retinal artery occlusion had a history of carotid surgery than controls $(p=0.0004)$. In addition, a higher proportion of cases in all groups except controls were having treatment for hypertension, although this difference was only significant in cases of retinal artery occlusion $(p=0.007)$ and all cases of retinal vein occlusion taken together $(\mathrm{p}=0.037)$ (Table 2$)$. Overall, a smaller proportion of cases than controls were smokers. A significantly higher proportion of cases of central retinal vein occlusion than controls had glaucoma ( $\mathrm{p}=$ 0.046). All disease groups had higher mean creatinine levels than the controls but in no group was this difference significant.

tHcy AS A RISK FACTOR FOR RETINAL VASCULAR OCCLUSIVE DISEASE

When compared with the control group, mean tHcy levels were higher in all the disease groups and this difference was significant in all groups except cases of branch retinal vein occlusion ( $p$ $=0.097$ ) (Table 1). On univariate analysis, elevated tHcy conferred a significantly increased risk of retinal vascular occlusive disease (arterial and venous disease combined; OR (95\%CI): 2.89 (1.52-5.50)) which remained significant following adjustment for the conventional risk factors of glaucoma, hypertension, and diabetes (OR 2.85 (95\% CI 1.43-5.68)) (Table 3). However, when retinal artery occlusive disease was considered alone, elevated tHcy was a significant risk factor only on univariate analysis (OR
2.53 (95\% CI 1.02-6.29)). While elevated tHcy was a significant risk factor for all vein occlusions combined on both univariate and multivariate analysis, this was not the case when branch vein occlusions were considered alone (Table 3).

\section{Discussion}

Elevated tHcy is both an independent risk factor for atherosclerotic vascular disease and interacts with other risk factors such as smoking and hypertension to increase cardiovascular disease risk. ${ }^{78}$ tHcy levels are determined by both genetic and nutritional factors and possible mechanisms of action of homocysteine on vascular endothelium include promotion of platelet activation, enhanced coagulability, and smooth muscle proliferation. ${ }^{6}$

Information relating abnormalities of homocysteine metabolism to retinal vascular occlusive disease are sparse and confined to two case reports and one small, uncontrolled series. ${ }^{17-19}$ In the latter, only post-methionine load homocysteine data were presented. ${ }^{19}$ The finding that elevated tHcy is an independent risk factor for central retinal vein occlusion is consistent with earlier findings implicating elevated tHcy in thrombus formation. ${ }^{4520}$ Furthermore, thrombus formation from rheological abnormalities other than elevated tHcy has been implicated in previous studies as a possible aetiological factor in central and hemiretinal vein occlusions ${ }^{1121-27}$ However, while central retinal vein occlusions are associated with similar risk factors to retinal arterial occlusive disease, local factors such as atherosclerotic retinal arteries compressing retinal veins at arteriovenous crossings may be more important in the aetiology of branch retinal vein occlusions. ${ }^{11}$ This could explain the difference in risk associated with elevated tHcy between central and branch retinal vein occlusions found in this study.

While tHcy levels were significantly higher in cases of retinal artery occlusion, the small number of patients with retinal artery occlusion included in this study precludes an examination of the relation between elevated tHcy, retinal artery occlusion, and two previously determined risk factors, carotid atheroma and hypertension. ${ }^{16}{ }^{28}{ }^{29}$ Contrary to expectations, a lower proportion of cases than controls were smokers. It is more likely that smokers had ceased at the time of their retinal event, or that they were underrepresented in this elderly population because of premature mortality, than that smoking protects against retinal vascular disease.

Recent reports indicate that both nutritional and genetic factors are important determinants of elevated tHcy levels and that dietary supplementation with folic acid can reduce tHcy. ${ }^{8-10}$ The clinical inference is that measurement, treatment, and monitoring of tHcy levels may be valuable in the management of patients with retinal vascular occlusive disease not only in young or atypical patients but in those with bilateral involvement, disease in an only eye, or those in whom widespread cardiovascular disease is suspected. 


\section{Conclusions}

Elevated tHcy is an independent risk factor for retinal vascular occlusive disease. In addition to an evaluation of all conventional cardiovascular risk factors, measurement of tHcy may be important in the initial investigation and management of patients with retinal vascular occlusive disease. Lowering elevated tHcy levels by administration of folic acid could improve prognosis in patients with such disease and randomised control trials to test this hypothesis are warranted.

The Research Foundation of the Royal Victoria Eye and Ear Hospital, Dublin, provided a grant for this study.

Maria Karabatzaki was supported by a student grant provided by the Health Research Board of Ireland.

Raymond Meleady was supported by an Irish Heart Raymond Meleady was supported by an Irish Heart
Foundation/Health Research Board of Ireland Unit Grant and by the European Union.

1 Carson NA, Neill DW. Metabolic abnormalities detected in a survey of mentally backward individuals in Northern Irea survey of mentally backward individua

2 Mudd SH, Levy HL, Skovby F. Disorders of transsulphuration. In: Schriver CR, Beaudet AL, Sly WS, Valle D, eds. tion. In: Schriver CR, Beaudet AL, Sly WS, Valle D, eds.
The metabolic basis of inherited disease. 6th ed. New York: The metabolic basis of inherited dised

3 McCully KS. Homocysteine theory of arteriosclerosis: development and current status. Atheroscler Rev 1983;11 157-246.

4 Den Heijer M, Rosendaal FR, Blom HJ, et al. Hyperhomocysteinemia and venous thrombosis: a meta-analysis Thromb Haemost 1998;80:874-7.

5 Den Heijer M, Koster T, Blom HJ, et al. Hyperhomocysteinaemia as a risk factor for deep-vein thrombosis. $N$ Engl $\mathcal{F}$ Med 1996;334:759-62.

6 Welch GN, Loscalzo J. Homocysteine and atherothrombosis. N Engl f Med 1998;338:1042-50.

7 Graham IM, Daly LE, Refsum HM, et al. Plasma homocysteine as a risk factor for vascular disease. The European Concerted Action Project. $\mathscr{f} A M A$ 1997;277: European

8 Boushey CJ, Beresford SA, Omenn GS, et al. A quantitative assessment of plasma homocysteine as a risk factor for vascular disease. Probable benefits of increasing folic acid intakes

9 Selhub J, Jacques PF, Wilson PWF, et al. Vitamin status and intake as primary determinants of homocysteinaemia in an elderly population. $\mathcal{F} A M A$ 1993;270:2693-8.

10 Clarke R, Collins R. Can dietary supplements with folic acid or vitamin B6 reduce cardiovascular risk? Design of clinical trials to test the homocysteine hypothesis of vascular disease. 7 Cardiovasc Risk 1998;5:249-55.
11 Williamson TH. Central retinal vein occlusion: what's the story? Br f Ophthalmol 1997;81:698-704.

12 Mitchell P, Smith W, Chang A. Prevalence and associations of retinal vein occlusion in Australia. The Blue Mountains eye study. Arch Ophthalmol 1996;114:1243-7.

13 The Eye Disease Case-Control Study Group. Risk factors for central retinal vein occlusion. Arch Ophthalmol 1996; 114:545-54.

14 Mangat HS. Retinal artery occlusion. Surv Ophthalmol 995;40:145-56.

15 Greven CM, Slusher MM, Weaver RG. Retinal arterial occlusions in young adults. Am f Ophthalmol 1995;120: $776-83$.

16 Destro M, Gragoudas ES. Arterial occlusion. In: Albert DM, Jakobiec FA, eds. Principles and practice of ophthalmology: clinical practice. Vol 3. Philidelphia: WB Saunders, 1994:727-35.

17 Biousse V, Newman NJ, Sternberg P Jr. Retinal vein occlusion and transient monocular visual loss associated with hyperhomocysteinemia. Am f Ophthalmol 1997;124:25760 .

18 Berg W van der, Verbraak FD, Bos PJ. Homocystinuria presenting as central retinal artery occlusion and longstanding thromboembolic disease. Br f Ophthalmol 1990;74:696-7.

19 Wenzler EM, Rademakers AJ, Boers GH, et al. Hyperhomocysteinemia in retinal artery and retinal vein occlusion. Am f Ophthalmol 1993;115:162-7.

20 Fiskerstrand T, Refsum H, Kvalheim G, et al. Homocysteine and other thiols in plasma and urine: automated determination and sample stability. Clin Chem 1993;39:263-71.

21 Mandel $\mathrm{H}$, Brenner B, Berant $\mathrm{M}$, et al. Coexistence of hereditary homocystinuria and factor V Leiden - effect on thrombosis. N Engl f Med 1996;334:763-8

22 Williamson TH, Rumley A, Lowe GD. Blood viscosity, coagulation and activated protein $\mathrm{C}$ resistance in central retinal vein occlusion: a population controlled study. $\mathrm{Br} F$ Ophthalmol 1996;80:203-8

23 Larsson J, Olafsdottir F, Bauer D. Activated protein C resistance in young adults with central retinal vein occlusion. Br f Ophthalmol 1996;80:200-2.

24 Dhote R, Bachmeyer C, Horrellou MH, et al. Central retinal vein thrombosis associated with resistance to activated protein C. Am f Ophthalmol 1995;120:388-9.

25 Williamson TH, Baxter GM, Lowe GD. Influence of age, systemic blood pressure, smoking and blood viscosity on orbital blood velocities. Br f Ophthalmol 1995;79:17-22.

26 Peduzzi M, Debbia A, Guerrieri F, et al. Abnormal blood rheology in retinal vein occlusion. A preliminary report. Graefes Arch Clin Exp Ophthalmol 1986;224:83-5.

27 Trope GE, Lowe GD, McArdle BM, et al. Abnormal blood viscosity and haemostasis in long-standing retinal vein occlusion. Br F Ophthalmol 1983;67:137-42.

28 Russel RW. The source of retinal emboli. Lancet 1968;2: 789-92.

29 Hollenhurst RW. Vascular status of patients who have cholesterol emboli in the retina. Am $\mathcal{f}$ Ophthalmol 1966;61: 1159-65. 